\title{
The "dating game": age differences at first sex of college students in Italy
}

\section{Maria Carella, Thaís García-Pereiro, Roberta Pace \& Anna Paterno}

\section{Genus}

Journal of Population Sciences

e-ISSN 2035-5556

Volume 76

Number 1

Genus (2020) 76:1-22

DOI 10.1186/s41118-020-00087-2 
Your article is published under the Creative Commons Attribution license which allows users to read, copy, distribute and make derivative works, as long as the author of the original work is cited. You may selfarchive this article on your own website, an institutional repository or funder's repository and make it publicly available immediately. 


\title{
The "dating game": age differences at first sex of college students in Italy
}

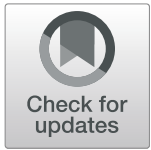

\author{
Maria Carella, Thaís García-Pereiro * ${ }^{\mathbb{D}}$, Roberta Pace and Anna Paterno
}

\author{
* Correspondence: t.garcia.pereiro@ \\ uniba.it \\ Università degli Studi di Bari "Aldo \\ Moro", Bari, Italy
}

\begin{abstract}
Researchers have devoted much attention both to the analysis of the first sexual experience and to how the couple was established, but little is still known about age differences of partners at their first sexual relationship. The availability of two highly comparable waves of a survey on the sexual behavior of college students in Italy (SELFY_Sexual and Emotional LiFe of Youth) carried out in 2000 and 2017 allowed us to study the predictors of age differences between partners at first sex, filling the existing gap on recent research. Results of multivariate analyses show important gender differences on mate selection: women tend to choose an older partner for having their first sexual experience and are less likely as men to be involved in age discordant first sex relationships with a younger partner. Age gaps between partners also influence age at sexual debut, which tends to occur earlier in a relationship with an older partner and later if having first sex with a younger partner. Another important predictor of the age gap is the type of relationship that linked the respondent to its partner at first sex. Our estimations indicate a lower likelihood of having had an older first sex partner for students who had their first sexual experience with the own boy/girl-friend or with a friend compared to those who have had it with a stranger. Finally, we have found a higher likelihood of first sex relationships among same-age partners relative to older partners through SELFY waves and small changes on variables influencing such relationships.
\end{abstract}

Keywords: Age differences, Mate matching, First sexual intercourse, College students, Italy

\section{Introduction}

Sexuality is a crucial individual component that involves beliefs and behaviors influenced by biological and psychological factors, personal and family values, moral and societal norms (Potki, Ziaei, Faramarzi, Moosazadeh, \& Shahhosseini, 2017). It is, therefore, an important aspect in the development of the own identity, in particular during adolescence and young adulthood. Nevertheless, the criteria of perception and selection of the partner have different meanings according to individual characteristics and relationships in which are embedded and cannot have the same meaning for men and women (Bozon, 2018). Consequently, from one sex to another, the feelings attached to "the first time" and the first sexual experience often appear at different ages and, especially, do not play identical roles in the transition to adulthood. As stated by

(c) The Author(s). 2020 Open Access This article is licensed under a Creative Commons Attribution 4.0 International License, which permits use, sharing, adaptation, distribution and reproduction in any medium or format, as long as you give appropriate credit to the original author(s) and the source, provide a link to the Creative Commons licence, and indicate if changes were made. The images or other third party material in this article are included in the article's Creative Commons licence, unless indicated otherwise in a credit line to the material. If material is not included in the article's Creative Commons licence and your intended use is not permitted by statutory regulation or exceeds the permitted use, you will need to obtain permission directly from the copyright holder. To view a copy of this licence, visit http://creativecommons.org/licenses/by/4.0/. 
Bozon and Rault (2012), the time elapsed between first sexual intercourse and first union formation (one of the most important markers of transition to adulthood) not only is becoming wider but also is gender related, being longer for men than for women.

The international literature has devoted much attention both to the analysis of the first sexual relationship and to how the couple has been established. However, few studies have considered these issues jointly by studying partners' characteristics at first sex and, more specifically, age differences at sexual debut.

Most sociodemographic research on age differences between partners and mate selection has been mostly focused on homogamy (Blau \& Schwartz, 1984; Kalmijn, 1998; Blackwell \& Lichter, 2004; Van de Putte et al., 2009; Schwartz \& Graf, 2009; Schwartz, 2013) stating that patterns of homogamy reflect age preferences in assortative mating based on searching for the similar (for a partner who resembles them).

It has been also highlighted a strong gender difference in age preferences of mates, being women more likely to have older partners and men more likely to search younger women (Buss, 1989). These preferences for older or younger mates seem to follow a universalistic rule, such as the matching principle, and are the opposite of the similarity-attraction rule of mate selection (like prefers like). Based on the former, scholars have explained such age preferences as a reflection of sex differences in lifehistory strategies (Kenrick, Gabrielidis, Keefe, \& Cornelius, 1996).

Researchers have examined the link between age differences and relationship dynamics, particularly between younger females and their older male partners with reference to the increasing risk of early sexual debut (VanOss Marín, Coyle, Gómez, Carvajal, \& Kirby, 2000; Heywood, Patrick, Smith, \& Pitts, 2015; Liu et al., 2015), missed contraceptive use (Miller, Clark, \& Moore, 1997; Glie, 1999; Ford, Sohn, \& Lepkowski, 2001; Manlove, \& Terry-Humen, E.\& Ikramullah, E., 2006), sexually transmitted diseases (Greenberg, Magder, \& Aral, 1992; Lee, Jennings, \& Ellen, 2003; Staras, Cook, \& Clark, 2009; Ryan, Franzetta, Manlove, \& Schelar, 2008; Senn \& Carey, 2011), unintended pregnancies (Zavodny, 2001; Bruckner \& Bearman, 2003) and coercive relationships (Darroch, Landry, \& Oslak, 1999; Volpe, Hardie, Cerulli, Sommers, \& Morrison-Beedy, 2013; Oudekerk, Guarnera, \& Reppucci, 2014). However, little is still known about age differences of partners at their first sexual relationship.

Concerning Italy, a study on SELFY (Sexual and Emotional LiFe of Youth) data, a survey carried out in 2000, highlighted that "first sexual intercourse occurred at a relatively adult age (around 18 for both genders), suggesting that there was no double standards for sexual initiation. There was furthermore a general correlation between the ages of interviewees and their partners, particularly as the majority of students had first sex with same-age partners. When, however, first sexual intercourse was not with same-age partners, males tended to choose younger partners, and females older ones" (Gabrielli, Pace, \& Paterno, 2004: 360). Moreover, in this study, a notable difference emerged with reference to the meaning of the first sexual intercourse, which among women occurred mainly in the context of a pre-existing affective relationship, while for men it represented a more individualistic and mostly physical experience.

A second wave of SELFY was carried out in 2017. Being data highly comparable among waves (Dalla-Zuanna, Caltabiano, Minello, \& Vignoli, 2019), we aim to contribute to the international debate on this topic investigating the predictors of age 
differences at first sex of university students in Italy following a comparative perspective between both samples of the survey. More specifically, we look at the following questions regarding the age gap in first sexual relationships: Are females more likely to have their first sexual experience with an older partner, while men more inclined to prefer a younger partner? Do age differences between first sex partners change due to the type of relationship? And finally, does the age difference between partners at first sex depend on whether an early sexual debut occurs?

This paper is organized as follows. It begins with the theoretical background and a review of previous research on partners' age gaps that is followed by a description of the methods and data used in this research. The next sections provide descriptive stats on age discordant relationships of students at their first sexual intercourse and then examine factors underlying age differences at first sex with a discussion of main implications concerned. The paper ends with a summary of key findings and some concluding remarks.

\section{Theoretical background}

When considering any kind of romantic exchange, the mainstream is homogamy in which the principle "like prefers like" rules, but there is a clear gender difference in how age is evaluated by individuals, being women mostly attracted to older men and men mostly attracted to younger women (Buss, 1989; Kenrick \& Keefe, 1992; Kenrick et al., 1996; Bech-Sørensen \& Pollet, 2016). Despite the former, researchers on mate selection and first sexual intercourse have paid little attention to age preferences, particularly age heterogamy within first sex relationships.

The study of age differences among couples has been approached by scholars throughout four different theoretical theories: social exchange, sociocultural norms, local market of potential partners, and evolutionary life-history theory.

One of the most cited theories of mate matching is the social exchange. This theory mixed utilitarianism and behaviorism to explain mate selection processes using something to exchange between potential partners (see, among others, Blau, 1964; Edwards, 1969). In this vein, the formation of unions is a process in which men and women search for the maximization of their utilities by exchanging their own resources (age, education, economic resources, physical attractiveness, etc.) with those of their partners. This means that, for example, men can try to exchange their socioeconomic status, while women can exchange their youth and physical attractiveness.

According to the sociocultural norms approach, individuals are embedded in a context plenty of norms, which have been internalized during socialization periods, that somehow rules individual choices and preferences. Thus, people tend to follow social norms in order to take mating decisions. In most western societies a slight age difference between partners is extremely common, being the man older than the woman (Ní Bhrolcháin, 2006). This has been interpreted as a logical consequence of the malebreadwinner model, where social roles attributed to the traditional division of labor are consistent with an older men-younger woman couple (Eagly \& Wood, 1999; Eagly, Wood, \& Diekman, 2000). Therefore, age preferences of both men and women should be considered a result of social beliefs regarding appropriate behavior and gender role attitudes. 
The supporters of the theory of the local market of potential partners state that the search for a potential mate is done within a pool full of candidates where the meeting evolves. This market has its own peculiarities and signs the pattern of availability of certain types of partners. Mate search and selection occur in a nonphysical place, called the partners' market, that has its own characteristics and exerts a more or less strong influence on both processes. The structure, in terms of composition, of this market directly affects the partner's availability influencing mate selection. Following this explanation, age differences between partners might depend on the age structure of the partners' market, being this place the one giving opportunities for contact and for interaction (Stauder, 2008, 2014; Eckhard \& Stauder, 2019). In this market, each potential partner competes with others to find a match (Stauder, 2008).

Finally, age preferences have also been explained using the evolutionary life-history perspective. According to this theoretical framework, among the determinants of mate matching appear not only the sociocultural explanations previously mentioned but also differences in the effort men and women produce in their lifespan for fertility and mate matching, as well as the role played by biological fitness and reproductive value in the search for a partner (Kenrick \& Keefe, 1992; Kenrick et al., 1996). In this sense, males will tend to search for female partners in the maximum of their reproductive potential and this might explain males' preference for younger women. There is only one exception: young males tend to prefer females of their own age but such preference changes while growing older (Buss, 1989). Age preferences of young females, instead, do not change over their life course, being more prone to prefer males who are older than themselves because they probably have already acquired enough resources to support the offspring.

Unfortunately, we were not able to explicitly test the abovementioned theoretical perspectives. This is basically due to data limitations. More specifically, we were not able to test neither the exchange theory nor the socio-cultural approach because even if we do count on some information about the socio-economic status of the respondent and its parents (mother and father), information regarding the socio-economic status and social role attitudes of the first sex partner is not available. Moreover, data collected do not allow to analyze the characteristics of the partners' market or meeting places in which respondents have chosen their first sex partners. Being our sample limited to university students, the hypotheses of the life-history perspective might not hold because respondents are too young to be already searching for the partner with whom starting the own family, instead, they might be experiencing a long period of "sexual youth" before engaging in a more definitive relationship (Bozon \& Rault, 2012). Therefore, we consider these theories as a useful framework to interpret the results of our analyses, but we have developed our research hypotheses based on the studies that considered specific aspects that our data allow to evaluate (as follows).

Some authors have examined some features of first sexual relationships in European countries (Henderson et al., 2002; Schubotz, Rolston, \& Simpson, 2004; Wight et al., 2008; Bozon \& Rault, 2012). They have shown that most young people has had their first sexual intercourse within a romantic relationship (Manning, Longmore, \& Giordano, 2000; Henderson et al., 2002; Wight et al., 2008), but Schubotz et al. (2004) have found that in Northern Ireland males were more likely than females to have had their first sexual experience when they first met their partner or shortly after. Another 
gender difference has also been observed in Scoltland by Wight et al. (2008), where young males have been more frequently involved in first sex with a casual partner. Gender differences regarding age discordant first sexual relations have also been identified. In general, the majority of young people were engaged with the same age (man with same age woman) or with older partners (woman with older man) at their sexual debut. However, behind this general trend, there is another gender-heterogenous behavior. Using data from the 2000 British National Survey of Sexual Attitudes and Lifestyles (Natsal, 2000), Mercer et al. (2006) have found that almost a third of men and over two-thirds of women had first sex with an older partner. Instead, having the first sexual intercourse with a younger partner is much more frequent among men than among women. Similar patterns have also been observed in Scotland (Wight et al., 2008) and France (Bozon \& Rault, 2012).

Empirical evidence from a survey on sexual behaviors conducted in 2005-2006 in France has revealed that interaction opportunities between the two genders are defined by the composition of local social settings (school, neighborhood, family, workplace) in which young adults are embedded, and that the more one interacts with older people, the higher the chances of getting involved with someone older. Here, places, where first sexual partners met each other, vary considerably by sex and social groups. More men than women meet their first sexual partner in daily living spaces, particularly in the place of study (secondary school and university). On the contrary, women more frequently find their first partner in more private meeting places and in the context of family networks. Among women, the preference towards privatization of sociability increases their chances to meet older sexual partners, a strategy that could be aimed at establishing a future life couple (Bozon \& Rault, 2012).

Although their attention was not focused on age differences at sexual debut, Kenrick et al. (1996) have shown that teenage males are more prone than females to have younger partners. Considering that females are interested in older males, their matching strategy remains expressing an interest in younger females. Other studies have confirmed that females, independently of their age, have a preference for males older than them (Wiederman, 1993; Kenrick, Keefe, Bryan, Barr, \& Brown, 1995; Buunk, Dijkstra, Kenrick, \& Warntjes, 2001; Buunk, Dijkstra, Fetchenhauer, \& Kenrick, 2002; Ní Bhrolcháin \& Sigle-Rushton, 2005; Antfolk et al., 2015; Antfolk, 2017).

Buunk et al. (2001) and Conroy-Beam and Buss (2019) have found that males' age preferences depend on the mating strategy, being age similarity more important for long-term than for short-term relationships. Thus, for short-term mating, males might prefer older women but, for long-term mating, they tend to favor younger females. Following this line, Buss and Schmitt (1993) and Young, Critelli, and Keith (2005) have described males' preferences for younger females for long-term mating than for a casual sexual encounter.

Miller et al. (1997), Manlove, and Terry-Humen, E.\& Ikramullah, E. (2006), KoonMagnin, Kreager, and Ruback (2010), and Loftus, Kelly, and Mustillo (2013) have highlighted that age gaps between partners are related to the timing of the first sexual experience. VanOss Marín et al. (2000) have reported that sixth-grade students who ever had a boyfriend or girlfriend at least 2 years older had increased odds of having had sex. Kaestle, Morisky, and Wiley (2002) have found that adolescent females involved with an older partner have higher odds of having intercourse with that partner 
than females with same-age partners and that the odds increase as females' age decreases.

Based on the former analyses, we have built three research hypotheses.

Research hypothesis 1: age differences between first sex partners are expected to show a higher likelihood of having had first sexual intercourse with an older partner for females than for males and on males being more likely to have had first sex with a younger partner.

Research hypothesis 2: age preferences of males are expected to change due to the mating strategy acted. Thus, we suppose differences to arise when distinguishing by the type of relationship established with the partner at the time of the first sexual intercourse. More specifically, on one hand, the likelihood of having had first sex with an older woman (vs. a same-age partner) will be lower when having had first sex with the own girlfriend (proxy for long-term matching) than with a stranger (proxy for short-term matching). On the other hand, a higher likelihood of having had first sex with a younger partner than with a same-age partner for those who shared this experience with their girlfriends instead of a stranger ${ }^{1}$.

Research hypothesis 3: a strong relationship is expected to be between partners' age differences and age at first sex. Thus, we suppose that both male and female odds of having had the first sexual experience with older partners will be higher for respondents that initiated their sexual life earlier. Due to the highest share of females involved with older partners, we also expected higher odds than those of males.

\section{Data and methods}

The study of age gaps between first sex partners is based on SELFY (Sexual and Emotional LiFe of Youths) survey carried out in the first half of 2017 in 28 Italian universities, that involved 8094 young people, aged between 18 and 26, attending undergraduate courses in economics and statistics. In this academic year (2016-2017) there were 1.670 million students enrolled in universities in Italy, a value only one percentual point lower than the one registered in 2000-2001. Such a trend demonstrates the stability of enrollment numbers in the country during this period. The share of females remained unchanged between academic years, representing around $55 \%$ of students enrolled.

For the purposes of the SELFY survey, the total number of students $\left(\mathrm{N}_{\mathrm{r}}{ }^{2}\right)$ enrolled in undergraduate courses on economics and statistics (only in public universities) was computed using data from the Italian Ministry of Education. Several courses in statistics or economics were randomly identified within fourteen macro-regions $(r)$ and all students attending a compulsory course were surveyed during a class. A certain number of students $\left(n_{r}\right)$ were surveyed for each macro-region. However, the proportion of surveyed students among the total number of students $(\mathrm{n} / \mathrm{N})$ differed according to the macro-region, thus, the weight $\left(N_{r} / N / n_{r} / n\right)$ was applied (Dalla-Zuanna et al., 2019).

\footnotetext{
${ }^{1}$ Studies have shown that male preferences regarding their partners' age change during the life course (Buss \& Schmitt, 1993; Buunk et al., 2001; Young et al., 2005; Conroy-Beam \& Buss, 2019). On the contrary, women's preference for older males tend to remain pretty much stable (Wiederman, 1993; Kenrick et al., 1995; Buunk et al., 2001, 2002; Ní Bhrolcháin \& Sigle-Rushton, 2005; Antfolk et al., 2015; Antfolk, 2017). ${ }^{2}$ Where $r$ is the sub-index that indicates the fourteen regions in which the Italian territory was divided in the sampling plan of the surveys (Dalla-Zuanna et al., 2019).
} 
Descriptive statistics and model specifications of this article have been accordingly weighted.

The survey carried out in 2017 replicates a survey held in 2000 in which 4998 students were interviewed using the same national sampling procedure and the same data collection technique (Dalla-Zuanna \& Crisafulli, 2004; Caltabiano, Dalla-Zuanna, \& Rosina, 2006; Billari, Caltabiano, \& Dalla-Zuanna, 2007). In both waves, similar questionnaires self-completed were filled by all students attending a lesson of a compulsory course under the discreet surveillance of both the teacher and a researcher of the team, who presented the survey and reassured students about the anonymity and use of the data. This process resulted in a practical non-existence of refusals to fill in the questionnaire in class, in both 2000 and 2017 (Dalla-Zuanna et al., 2019).

The aim of the two surveys was to give an updated picture of sexual and emotional attitudes and behaviors among university students in Italy. The comparison between the two waves has provided us with an insight into the changes that have occurred over the past 17 years.

The sample is of course not supposed to be representative of the universe of undergraduate students in Italy but relevant heterogeneity with regard to both sexuality and affective behaviors has been identified in SELFY respondents by researchers of the national team, which makes students interviewed an extremely interesting group to be studied. In both waves (2000 and 2017), data were post-stratified at the macro-region level to obtain representative results at the national level.

Regarding the representativeness of SELFY samples when considering university students, Dalla-Zuanna et al. (2019) have tested whether and how sexual behaviors of SELFY respondents differ from the mean of their peers. Researchers have followed a twofold comparison on available data. When results were compared to a nationally representative survey on sexual behaviors conducted in 2006 (Barbagli et al., 2010), behaviors reported on SELFY samples seemed in line with those of tertiary educated young people and university students, who are less sexually precocious than their average peers with lower educational levels. When 2017 SELFY sample was compared to a sample of 451 political science students of the University of Padua from a survey conducted the same year, findings of Dalla-Zuanna et al. (2019) allowed to identify a trade-off between the type of curriculum and sexual practices, given that SELFY respondents initiated their sexual life later and held more traditional sexual behaviors than their political science peers.

We applied two important restrictions to our SELFY samples due to our subject of study. First, we limited both samples to college students who already have had their first sexual intercourse by the time of the surveys; and, second, to those who declared the age of their first sex partner, obtaining a sample of 2530 in 2000 and 4410 in 2017. Nearly $34 \%$ of the respondents of the first wave have not had a full sexual intercourse by the time of the survey. In the 2017 wave, the share of respondents significantly decreased reaching $19.8 \%$. After performing descriptive analyses, we applied multinomial and binary logistic regressions to examine the relationship between the characteristics and the behaviors of our sample of college students.

Our models predicted the relative likelihood of an individual (female or male) to has had the first sexual experience with an older partner as opposed to has had it with a same age or younger partner (the reference category), conditional on the key predictors. 
In particular, our dependent variable is formed by three categories according to respondents' age difference with their first sexual partner (age discordant first sex relationships): those who have had first sex with a partner two or more years older, those who have had first sex with a partner of similar age (less than 2 years older or younger) and those who have had first sex with a partner two or more years younger. These categories were built following a criterion based on the sample distribution: making extreme groups (those having had sex with younger and with older partners) enough numerically consistent for multivariate analyses.

More in detail, as a first step of our analysis, a multinomial logistic regression model is used for the multivariate analysis of age discordant first sex relationship. We start with a model for the entire sample (models 1 and 2), in which we contrast women and men in $2000(n=2530)$ and $2017(n=4410)$. This method is used to investigate the association between our explanatory variables and the direction of age gaps between partners (older partner and younger partner versus same age partner).

In a second step, separate models were fitted for men (models 3 and 4) and women (models 5 and 6), comparing the sample of both waves. Gender differences in age mating patterns have been well documented in research on mate selection (Wiederman, 1993; Kenrick et al., 1995; Buunk et al., 2001; Ní Bhrolcháin \& SigleRushton, 2005; Antfolk, 2017), but it remains unclear which factors may differently affect women and men. Due to the low percentage of women having had first sex with a younger partner (3\%), for the female subsample only $(n=1629,2000 ; n=$ 2412, 2017) we fitted binomial models (models 5 and 6) that merge two categories of the previous multinomial specification. Thus, age differences between partners are divided into students who have had first sex with an older partner and those who have had it with younger or same-age partners. For the male subsample $(n=$ 901, 2000; $n=1998$, 2017), we also employ multinomial logistic regression (models 3 and 4). Summarizing, we built 6 model specifications (shown in Table 7) which have been numbered from 1 to 6 (model 1...to model 6) and grouped in columns based on "both genders," "males" and "females" for each SELFY wave (2000 and 2017, respectively).

Variables included in multivariate analyses are presented in Table 1. The first group of independent variables (gender, type of relationship with first sex partner, and age at sexual debut) has been considered as main determinants of age differences between partners at first sex, while other covariates were included as control variables (grouped on characteristics of the family of origin, proxies for potential meeting places, and atrisk behaviors).

In detail, the three groups of control variables that research has found to be relevant for the study of youth' sexual behaviors, are the following:

\section{Characteristics related to the family of origin}

Extensive research has shown that both family structures and processes are associated with sexual behaviors adopted during adolescence and early youth (Wight, Williamson, \& Henderson, 2006; Aspy et al., 2007), but only a few have analyzed which and how characteristics related to the family of origin influence age differences between sexual partners (Darroch et al., 1999; Ford, Sohn, \& Lepkowski, 2003; Manlove, \& Terry- 
Table 1 Dependent variables and covariates included in multinomial and binary logistic regression models

\begin{tabular}{ll}
\hline Variable & Definition \\
\hline $\begin{array}{l}\text { Dependent variables } \\
\begin{array}{l}\text { Type of age discordant first sex } \\
\text { relationships (3 categories) }\end{array}\end{array}$ & $\begin{array}{l}\text { Categorical. Same age partner (reference category): if the partner was } \\
\text { less than 2 years older or younger than respondent. Younger partner: if } \\
\text { the partner was two or more years younger than respondent. Older } \\
\text { partner: if the partner was two or more years older than respondent. }\end{array}$ \\
$\begin{array}{l}\text { Type of age discordant first sex } \\
\text { relationships (2 categories) }\end{array}$ & $\begin{array}{l}\text { Binary. Same age/younger partner (reference category): if the partner } \\
\text { was less than 2 years older or younger and if the partner was two or } \\
\text { more years younger than respondent. Older partner: if the partner was } \\
\text { two or more years older than respondent. }\end{array}$
\end{tabular}

Independent variables

$$
\text { Key variables }
$$

Gender

Type of relationship with first sex partner

Age at sexual debut

\section{Dummy. Coded 1 for female students and 0 for male students.}

Categorical. Coded 1 for those having their first sexual experience with a stranger (reference category), 2 for those which had first sex with friends, and 3 for those whose first sex partner was the own boy/ girlfriend.

Categorical. Coded 1 (early debut) if the student has had first sex 1 year or more before the mean age at first sex of the distribution, 2 (mean debut), if the student has had first sex 1 year earlier or 1 year later than the mean, and 3 (late debut) if age at first sex was at least 1 year older than the mean (see mean age values in the descriptive results section).

control variables

Characteristics related to the family of origin

Dual earner family

Type of emotional relationship with father

Type of emotional relationship with mother

Proxies of meeting places

Older brother

Working regularly

At-risk behaviors

Frequent smoker

Drunkenness
Dummy. Coded 1 for students whose parents were both working at age 14-15 and 0 for those who lived on a single earning family.

Dummy. Coded 1 for students having a balanced relationship with father at age 14-18 and 0 otherwise. mother at age 14-18 and 0 otherwise.

Dummy. Coded 1 for students having at least one older brother (older male sibling) and 0 for those without older brothers.

Dummy. Coded 1 for students regularly working and 0 for those in other working situations (including not working).

Dummy. Coded 1 for students who smoke frequently (daily smokers) at age $14-15$ and 0 otherwise.

Dummy. Coded 1 for college students who get drunk frequently by the time of the survey and 0 otherwise.
Dummy. Coded 1 for students having a balanced relationship with

Humen, E.\& Ikramullah, E., 2006). Depending on data availability we considered the following two variables:

- Dual-earner family. Some authors have stated that adolescents' sexuality changes according to the level of gender equality of their surrounding environments, where less egalitarian gender norms might threaten their sexual health (Marston \& King, 2006; De Meyer et al., 2014). A dual-earner family could be considered a more gender-equal environment in which having grown up respect to the one lived by students coming from single-earner (predominantly male breadwinner) families (Fahlén, 2015). 
- Type of emotional relation with father and mother. According to the literature, parents might influence sexual and reproductive decisions of their adolescent children (Borawski, Ievers-Landis, Lovegreen, \& Trapl, 2003; Huebner \& Howell, 2003; Aspy et al., 2007). In particular, the quality of the relationship between the youth and his/her parents might affect not only the timing of the first sexual relationship but also the number of sexual partners (Longmore, Eng, Giordano, \& Manning, 2009; Brauner-Otto \& Axinn, 2010) and the adoption of healthy sexual behaviors of youth and adolescents (Rodgers, 1999; Parkes, Henderson, Wight, \& Nixon, 2011).

\section{Potential meeting places}

None of SELFY surveys asked about where and when the respondent met his/her first sexual partner. However, models include these two proxies (older brother and working regularly) that allow to differentiate among respondents' social universes (Bozon \& Rault, 2012). Both variables can give some insights about where students probably met their potential partners (family and workplace), outside the typical school-university meeting place in which they are embedded.

\section{At-risk behaviors}

There is a large body of evidence showing that risky behaviors influence young peoples' sexual decisions (Santelli, Robin, Brener, \& Lowry, 2001; Cooper, 2002; Ritchwood, Ford, DeCoster, Sutton, \& Lochman, 2015). Depending on data availability we considered the following:

- Frequent smoker (for students who smoke frequently at age 14-15 and 0 otherwise), since early sexual debut and multiple partners, have both been associated with daily smoking (Poulin \& Graham, 2001; Doku, 2012)

- Drunkenness, since youth who are frequent consumers of alcohol not only tend to engage in sexual risk behaviors (Cooper, 2002; Scott-Sheldon et al., 2016) but also report an earlier sexual debut (Bellis et al., 2008; Lomba, Apóstolo, \& Mendes, 2009) and a higher number of sexual partners (Dogan, Stockdale, Widaman, \& Conger, 2010; Ramrakha et al., 2013).

Several independent variables were considered on previous specifications built (intact family, parents' level of education and occupational characteristics, importance of religion, clubbing at different ages, etc.), but their inclusion gave not statistically significant coefficients and did not improve the fit of our models, so were dropped of final models included in this version of the paper.

\section{Descriptive results}

The median age at first sexual intercourse in the first wave (2000) was 18.00 and 17.92 for male and female respondents, respectively. The corresponding figures of the second wave (2017) are indicating a decrease on age at first sex (median age 17.50 and 17.25, in that order). This trend concerns youth and adolescents in several European countries since the twentieth century (Bozon \& Kontula, 1998). A review of the literature on first 
sexual intercourse by Hawes, Wellings, and Stephenson (2010) has stressed the conspicuous decline in the age at which young people become sexually active and the convergence of the timing of the sexual debut between men and women. The analyses of changing patterns of sexual behavior followed by Bajos et al. (2010) with data from three French surveys on sexuality (conducted in 1970, 1992, and 2006), confirm a sharp decrease on median age at first sexual intercourse for both men and women over time.

Regarding changes on age patterns between SELFY's waves, there has been an increase on the share of respondents that have had an early sexual debut (have had their first sexual intercourse 1 year or more before the mean age at first sex of the distribution) from $27.1 \%$ in 2000 to $30.9 \%$ in 2017 . However, when disaggregating by gender, male figures remain almost unchanged (27.1\% in 2000 to $28.4 \%$ in 2017) being female's behavior responsible for the general increasing trend previously mentioned $(27.1 \%$ in 2000 to $33.0 \%$ in 2017). This result is in line with previous findings on SELFY obtained by Dalla-Zuanna et al. (2019) indicating a reduction on age at first sexual intercourse between waves and a gender convergence of first sexual behaviors.

Even if it is not possible to distinguish between homosexual and heterosexual first sexual intercourses-the gender of the first sex partner is not available-the question about sexual experiences with same-gender partners provides important information regarding its incidence. The share of students who have had at least one sexual experience with a same-gender partner has doubled up in 17 years: from $5.1 \%$ in 2000 to $10.9 \%$ in 2017. This general increase hides important gender differences because it is almost completely attributable to females' homosexual experiences: $4.3 \%$ declared having had at least one same-gender sexual experience in 2000 while in 2017 this value reached $14.9 \%$ (data are not shown here but are available upon request).

When looking at the percentage distribution of the type of discordant relationships at first sex of both SELFY waves (Fig. 1) two distinctive characteristics arise. First, in line with the literature on mate matching and age preferences (Buss, 1989; Kenrick et al., 1996; Bech-Sørensen \& Pollet, 2016; Antfolk, 2017), most women have had their first sexual experience with older partners while men had it with same-age partners. Second, despite the former, there is a trend shared by males and females: the proportion of

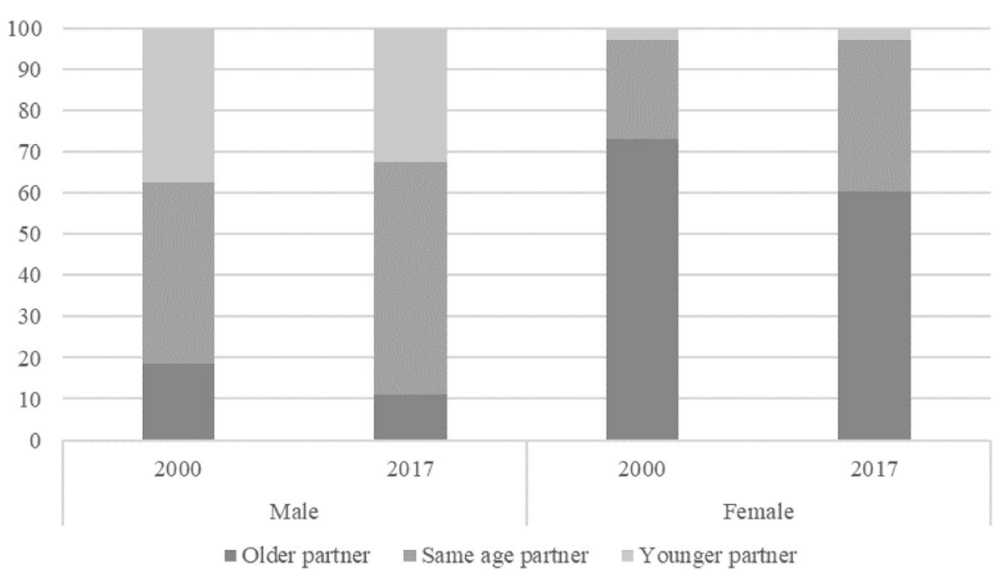

Fig. 1 Percentage distribution of type of discordant relationships at first sex by gender. Source: Own elaborations on SELFY 2000 and 2017 data 
students involved with same-age partners at first sex significantly increases between 2000 and 2017 (from $23.9 \%$ to $36.6 \%$ for females and from $43.7 \%$ to $56.6 \%$ for males).

Descriptive analyses also investigate female and male students sexual age differences through the age of the first sexual partner. Tables 2 and 3 show matrices of age at first sexual intercourse of 2017 survey respondents (females and males, respectively) and their partners. The main diagonal shows percentages of same age first sex relationships, the upper triangular represents relationships where the partner is younger while the lower triangular displays percentages of relationships in which the partner was older than the respondent at first sex.

By looking at the upper triangular of the matrix (Table 2) it is clearly visible that most females, independently of their age at first sex were involved with older partners and their first sex partner's age tends to increase at older ages. The highest percentage of age homogeneity at first sex among female college students is observed at age 18-19 (44.4\%) and the lowest at 22-23 years old (3.7\%). For example, $22.3 \%$ of those who have had their first sexual intercourse before their 16th birthday had a partner who was 1819 years old. On the other hand, $42.9 \%$ of females who had their first sexual experience later (at 22-23 years old) have had a first sex partner who was 26-27 years old.

As expected, the main diagonal confirms that most male college students tend to be involved in age homogeneous first sexual relationships; the level of age homogamy is higher at younger ages (Table 3). On the contrary, their female counterparts exhibit a higher prevalence of age discordant first sex relationships, particularly after the 20th birthday, as shown by the percentages displayed on the lower triangular of the age matrix (Table 2).

The trend to higher levels of age homogeneity at first sex is again confirmed when comparing age matrices of partners at first sex of 2000 SELFY wave (Tables 4 and 5). In fact, the proportion of the main diagonals for both male and female college students are systematically higher in 2017 if compared to the former SELFY wave, while the highest increments were observed among females that had first sex before their 18th birthday and among males initiating their sexual life between 20 and 23 years old.

Regarding the type of relationship with the partner at first intercourse, even if the normative pattern is to have it with the own boy/girlfriend (87.3\%), some students reported having first sex outside dating relationships choosing a friend (11.5\%). The share of college students who have had their first sexual relationship with a stranger in the

Table 2 Age matrices at first sexual intercourse of female survey respondents and their male partners, 2017 SELFY wave

\begin{tabular}{|c|c|c|c|c|c|c|c|c|}
\hline \multicolumn{9}{|c|}{ Respondents' age at first sex } \\
\hline \multirow{10}{*}{ 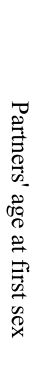 } & & $<16$ & $16-17$ & $18-19$ & $20-21$ & $22-23$ & $24-25$ & Total \\
\hline & $<16$ & 30.2 & 5.5 & 0.0 & 0.0 & 0.0 & 0.0 & 10.3 \\
\hline & $16-17$ & 42.2 & 34.1 & 9.7 & 0.8 & 0.0 & 0.0 & 27.6 \\
\hline & $18-19$ & 22.3 & 35.4 & 44.4 & 5.2 & 0.0 & 0.0 & 32.9 \\
\hline & $20-21$ & 4.0 & 15.5 & 24.7 & 35.8 & 16.0 & 0.0 & 16.0 \\
\hline & $22-23$ & 0.4 & 6.2 & 10.2 & 30.5 & 3.7 & 0.0 & 6.9 \\
\hline & $24-25$ & 0.2 & 2.1 & 6.3 & 16.4 & 29.4 & 23.0 & 3.6 \\
\hline & $26-27$ & 0.2 & 0.3 & 1.7 & 5.0 & 42.9 & 0.0 & 1.0 \\
\hline & $>27$ & 0.5 & 0.9 & 3.0 & 6.3 & 8.0 & 77.0 & 1.7 \\
\hline & Total & 100.00 & 100.0 & 100.0 & 100.0 & 100.0 & 100.0 & 100.0 \\
\hline
\end{tabular}

Source: Own elaborations on SELFY 2017 data 
Table 3 Age matrices at first sexual intercourse of male survey respondents and their female partners, 2017 SELFY wave

\begin{tabular}{|c|c|c|c|c|c|c|c|c|}
\hline & & \multicolumn{7}{|c|}{ Respondents' age at first sex } \\
\hline & & $<16$ & $16-17$ & $18-19$ & $20-21$ & $22-23$ & $24-25$ & Total \\
\hline \multirow{9}{*}{ 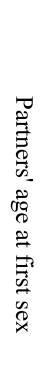 } & $<16$ & 78.1 & 37.1 & 6.9 & 0.5 & 5.1 & 0.0 & 34.5 \\
\hline & $16-17$ & 19.9 & 51.3 & 42.7 & 7.9 & 5.1 & 0.0 & 39.2 \\
\hline & $18-19$ & 1.1 & 9.7 & 42.3 & 40.5 & 2.4 & 0.0 & 19.5 \\
\hline & $20-21$ & 0.4 & 0.8 & 3.2 & 38.2 & 32.5 & 0.0 & 3.6 \\
\hline & $22-23$ & 0.5 & 0.4 & 2.7 & 7.8 & 52.6 & 0.0 & 1.8 \\
\hline & $24-25$ & 0.0 & 0.5 & 0.8 & 1.2 & 2.4 & 0.0 & 0.6 \\
\hline & $26-27$ & 0.0 & 0.0 & 0.2 & 3.1 & 0.0 & 100.0 & 0.2 \\
\hline & $>27$ & 0.1 & 0.3 & 1.2 & 0.8 & 0.0 & 0.0 & 0.6 \\
\hline & Total & 100.0 & 100.0 & 100.0 & 100.0 & 100.0 & 100.0 & 100.0 \\
\hline
\end{tabular}

Source: Own elaborations on SELFY 2017 data

sample is low (1.3\%) and is mostly male (3 out of 4 are male), indicating a partnering behavior more oriented to sexual activity and less responsive to emotional connections. These encounters seem to go further the typical hookup by including sexual intercourses, thus, it is not about having casual sex with a friend (a more conventional dating relation) but deciding to have the first sexual experience with a stranger completely outside a dating context. It is interesting to note that variations between SELFY waves' support the hypotheses of "feminization" of male behavior and "masculinization" of female behavior already pointed out by Dalla-Zuanna et al. (2019): There are no significant changes on the share of students having first sex with strangers, but the percentage of male students is reduced by 13 percentual points between 2000 and 2017 (60.4\%) (data are not shown here but are available on request).

Table 6 shows the percentage distribution of age differences between first sex partners by gender, type of the relationship, and age at sexual debut for 2000 and 2017 SELFY waves.

The age differences between men and women highlight that age homogeneity at first sex is quite gender balanced, even if the percentage of males who had first sex with same-age partners increased between waves (from 53.0\% to 56.5\%), while agediscordant relationships at first sexual intercourse are mostly male if the partner is younger and predominantly female if the partner is older.

Table 4 Age matrices at first sexual intercourse of female survey respondents and their male partners, 2000 SELFY wave

\begin{tabular}{|c|c|c|c|c|c|c|c|c|}
\hline \multirow{11}{*}{ 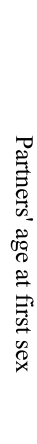 } & & \multicolumn{7}{|c|}{ Respondents' age at first sex } \\
\hline & \multirow[b]{2}{*}{$<16$} & $<16$ & \multirow[t]{2}{*}{$16-17$} & $18-19$ & $20-21$ & $22-23$ & $24-25$ & Total \\
\hline & & 15.1 & & 0.2 & 0.0 & 0.0 & 0.0 & 2.7 \\
\hline & $16-17$ & 32.4 & 20.0 & 4.6 & 2.0 & 0.0 & 0.0 & 14.1 \\
\hline & $18-19$ & 35.2 & 40.5 & 34.6 & 11.6 & 3.8 & 0.0 & 33.8 \\
\hline & $20-21$ & 10.4 & 24.3 & 31.5 & 34.9 & 10.5 & 0.0 & 25.2 \\
\hline & $22-23$ & 3.2 & 8.6 & 16.8 & 25.7 & 40.8 & 0.0 & 13.1 \\
\hline & $24-25$ & 2.7 & 2.5 & 6.9 & 10.0 & 16.3 & 2.4 & 5.1 \\
\hline & $26-27$ & 0.5 & 2.1 & 2.4 & 8.9 & 16.2 & 40.3 & 3.3 \\
\hline & $>27$ & 0.5 & 0.6 & 3.0 & 6.9 & 12.4 & 57.3 & 2.7 \\
\hline & Total & 100.0 & 100.0 & 100.0 & 100.0 & 100.0 & 100.0 & 100.0 \\
\hline
\end{tabular}

Source: Own elaborations on SELFY 2000 data 
Table 5 Age matrices at first sexual intercourse of male survey respondents and their female partners, 2000 SELFY wave

\begin{tabular}{|c|c|c|c|c|c|c|c|c|}
\hline \multirow{10}{*}{ 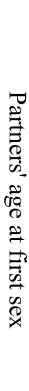 } & & \multicolumn{7}{|c|}{ Respondents' age at first sex } \\
\hline & & $<16$ & $16-17$ & $18-19$ & $20-21$ & $22-23$ & $24-25$ & Total \\
\hline & $<16$ & 66.7 & 29.1 & 11.8 & 2.4 & 0.0 & 0.0 & 26.0 \\
\hline & $16-17$ & 27.3 & 49.5 & 37.8 & 20.6 & 0.0 & 0.0 & 37.5 \\
\hline & $18-19$ & 3.5 & 13.3 & 34.7 & 38.9 & 24.3 & 0.0 & 22.2 \\
\hline & $20-21$ & 1.7 & 5.9 & 11.6 & 25.1 & 8.1 & 57.5 & 9.2 \\
\hline & $22-23$ & 0.8 & 1.1 & 2.2 & 6.5 & 34.5 & 0.0 & 2.6 \\
\hline & $24-25$ & 0.0 & 0.0 & 0.9 & 2.2 & 30.0 & 42.5 & 1.4 \\
\hline & $>26$ & 0.0 & 1.0 & 1.1 & 4.3 & 3.0 & 0.0 & 1.2 \\
\hline & Total & 100.0 & 100.0 & 100.0 & 100.0 & 100.0 & 100.0 & 100.0 \\
\hline
\end{tabular}

Source: Own elaborations on SELFY 2000 data

Interesting information arise when looking at the sexual debut of college students by age differences in first sex relationships. Percentage distributions for the 2017 wave show that $42.7 \%$ of respondents involved in first sex with same-age partners experienced a mean sexual debut, that almost $39 \%$ of respondents having had their first sexual experiences with partners younger than themselves had a late start, and $38.2 \%$ of those sharing first sex with an older partner have had an early sexual debut. When comparing these figures with those of the 2000 wave emerges a higher share of early starters independently of the type of age-discordancy between partners, becoming the most important category among those who had their first sexual intercourse with an older partner.

\section{Multivariate results and discussion}

Table 7 depicts multinomial logistic regression models built to analyze the relative risk of have had the first sexual experience with an older or a younger partner versus sameage partner, after controlling by the effects of main explanatory variables (gender, relationship with partner at first sex and age at sexual debut) and controlling for some

Table 6 General descriptive statistics of first set of models (column percentages of key determinants for both SELFY waves)

\begin{tabular}{|c|c|c|c|c|c|c|}
\hline & \multicolumn{3}{|l|}{2000} & \multicolumn{3}{|l|}{2017} \\
\hline & Older & Younger & Same-age & Older & Younger & Same-age \\
\hline \multicolumn{7}{|l|}{ Gender } \\
\hline Male & 11.3 & 87.7 & 53.0 & 12.8 & 91.3 & 56.5 \\
\hline Female & 88.7 & 12.3 & 47.0 & 87.2 & 8.7 & 43.51 \\
\hline \multicolumn{7}{|l|}{ Type of relationshi } \\
\hline Stranger & 2.9 & 1.2 & 1.1 & 1.7 & 1.4 & 0.8 \\
\hline Friend & 9.6 & 11.0 & 12.9 & 11.4 & 10.4 & 11.9 \\
\hline Boy/girlfriend & 87.5 & 87.8 & 86.0 & 86.9 & 88.2 & 87.3 \\
\hline \multicolumn{7}{|l|}{ Sexual debut } \\
\hline Early start & 32.2 & 16.6 & 23.2 & 38.2 & 18.4 & 29.2 \\
\hline Mean start & 43.3 & 42.7 & 46.2 & 37.6 & 43.3 & 42.7 \\
\hline Late start & 24.5 & 40.7 & 30.6 & 24.2 & 38.3 & 28.1 \\
\hline Row percentage & 55.5 & 30.4 & 14.1 & 38.1 & 45.6 & 16.3 \\
\hline N & 1345 & 349 & 836 & 1729 & 755 & 1926 \\
\hline
\end{tabular}

Source: Own elaborations on SELFY 2000 and 2017 data 
characteristic of the family of origin of respondents (growing in a dual-earner family, the type of emotional relationship with both father and mother and having at least one older brother) and some at-risk behaviors (being a frequent smoker and drunkenness). Specifications 1 and 2 are general multinomial models for the first and the second SELFY waves (model 1 for 2000 and model 2 for 2017).

The main outcomes we can draw from these models (first two columns of Table 7) confirm our descriptive findings, even after controlling for independent variables, and show firstly that, compared to men, women were more likely to have had first sex with an older partner. Secondly, our results confirm also, net of other covariates, that women were less likely than men to be involved in age discordant first sex relationships with a younger partner. Therefore, our first hypothesis was clearly verified: i.e., women tend to choose an older partner also for their first sexual experience. This outcome is in line with previous studies on age preferences which have always remarked the existence of clear gender differences on mate selection (Buss, 1989; Kenrick \& Keefe, 1992; Kenrick et al., 1995; Kenrick et al., 1996; Wiederman, 1993; Buunk et al., 2002; BechSørensen \& Pollet, 2016).

Based on these results, we can observe that the type of relationship that linked the respondent to its partner at first sex affects the age gap between them in a different manner. First, the relative risk ratios indicate a lower likelihood of having had an older first sex partner for students who had their first sexual experience with the own boy/girlfriend or with a friend compared to those who have had it with a stranger. Meanwhile, the type of relationship is not significant for having had first sex with a younger partner respect to a partner of the same age. These results confirm, although partially, our second hypothesis.

Another important determinant differently affecting the type of the age gap between respondents and their partners at first sex is the age at sexual debut. Students who had a mean or a late sexual initiation were less likely to have had first sex with an older partner. This finding confirms our third hypothesis: age gaps between partners also influence age at sexual debut, which tends to occur earlier in a relationship with an older partner (Vanoss Marín et al., 2000; Kaestle et al., 2002). The contrary is observed when comparing first sex relationships with younger and same-age partners. Here, the risk of a downward age first sex experience (with a younger partner) is higher among those who had a mean or a late sexual debut relative to those who have experienced an early debut.

It is interesting to note the increase on the share of students that had their first sexual intercourse with same-age partners. In fact, a simple multinomial regression merging both waves (data are not shown here but are available upon request) shows that the likelihood of have had first sex with an older partner rather than with a same-age partner was 1.8 times higher in the first wave than in the second without significant changes between younger and same-age partners at first sex.

Models run separately for females and males give clear pictures about gender differences on age discordant relationships at first sex. Models 3 and 4 are multinomial regressions on males, while models 5 and 6 are binary logistic regressions on females. Models 3 (males) and 5 (females) regard the first wave (2000) and models 4 (males) and 6 (females) were run on the second (2017). Our main results show that engaging on the first sexual intercourse with an older partner is not a 
Table 7 Results of multinomial (for both genders and men) and binary (for women) logistic regression models (relative risks and odd ratios) of partners' age differences at first sex on key determinants and control variables for 2000 and 2017 SELFY waves

\begin{tabular}{|c|c|c|c|c|c|c|}
\hline & \multicolumn{2}{|c|}{ Both genders } & \multicolumn{2}{|l|}{ Males } & \multicolumn{2}{|l|}{ Females } \\
\hline & $\begin{array}{l}\text { Model } 1 \\
2000\end{array}$ & $\begin{array}{l}\text { Model } 2 \\
2017\end{array}$ & $\begin{array}{l}\text { Model } 3 \\
2000\end{array}$ & $\begin{array}{l}\text { Model } 4 \\
2017\end{array}$ & $\begin{array}{l}\text { Model } 5 \\
2000\end{array}$ & $\begin{array}{l}\text { Model } 6 \\
2017\end{array}$ \\
\hline \multicolumn{7}{|l|}{ Older partner } \\
\hline \multirow[t]{2}{*}{ Women } & $12.39^{* * *}$ & $10.60^{* * *}$ & - & - & - & - \\
\hline & (1.599) & $(0.984)$ & - & - & - & - \\
\hline \multirow[t]{2}{*}{ Friend } & $0.209^{* * *}$ & $0.229^{* * *}$ & $0.237^{* * *}$ & $0.180^{* * *}$ & 0.184 & 0.983 \\
\hline & $(0.0887)$ & $(0.0836)$ & $(0.111)$ & $(0.0741)$ & $(0.196)$ & $(0.568)$ \\
\hline \multirow[t]{2}{*}{ Boy/girl friend } & $0.107^{* * *}$ & $0.130^{* * *}$ & $0.110^{* * *}$ & $0.0696^{* * *}$ & $0.107^{* *}$ & 0.726 \\
\hline & $(0.0438)$ & $(0.0461)$ & $(0.0494)$ & $(0.0277)$ & $(0.111)$ & $(0.406)$ \\
\hline \multirow[t]{2}{*}{ Mean sexual debut } & $0.551^{* * *}$ & $0.627^{* * *}$ & $0.478^{* * *}$ & 0.750 & $0.520^{* * *}$ & $0.569^{* * *}$ \\
\hline & $(0.0701)$ & $(0.0563)$ & $(0.111)$ & $(0.138)$ & $(0.0819)$ & $(0.0597)$ \\
\hline \multirow[t]{2}{*}{ Late sexual debut } & $0.399^{* * *}$ & $0.562^{* * *}$ & 0.737 & 0.936 & $0.300^{* * *}$ & $0.461^{* * *}$ \\
\hline & $(0.0564)$ & $(0.0567)$ & $(0.193)$ & $(0.189)$ & $(0.0499)$ & $(0.0531)$ \\
\hline \multirow[t]{2}{*}{ No (single earner) } & 0.953 & $1.262^{* * *}$ & $0.607^{* *}$ & 1.167 & 1.079 & $1.274^{* * *}$ \\
\hline & $(0.0981)$ & $(0.100)$ & $(0.130)$ & $(0.192)$ & $(0.128)$ & $(0.115)$ \\
\hline \multirow{2}{*}{$\begin{array}{l}\text { Balanced relationship } \\
\text { (father) }\end{array}$} & 0.903 & 1.075 & $0.598^{* *}$ & 1.044 & 1.021 & 1.094 \\
\hline & $(0.102)$ & $(0.104)$ & $(0.142)$ & $(0.210)$ & $(0.129)$ & $(0.119)$ \\
\hline \multirow{2}{*}{$\begin{array}{l}\text { Balanced relationship } \\
\text { (mother) }\end{array}$} & 1.216 & 0.884 & 1.314 & $0.489^{* *}$ & 1.198 & 1.007 \\
\hline & $(0.167)$ & $(0.127)$ & $(0.391)$ & $(0.146)$ & $(0.180)$ & $(0.157)$ \\
\hline \multirow[t]{2}{*}{ Working regularly } & 1.216 & 0.994 & $1.888^{* *}$ & 0.736 & 0.945 & 1.086 \\
\hline & $(0.185)$ & $(0.102)$ & $(0.501)$ & $(0.159)$ & $(0.163)$ & $(0.128)$ \\
\hline \multirow[t]{2}{*}{ Older brother } & $1.474^{* * *}$ & $1.202^{* *}$ & 1.186 & 1.204 & $1.566^{* * *}$ & $1.245^{* *}$ \\
\hline & $(0.171)$ & $(0.0983)$ & $(0.269)$ & $(0.199)$ & $(0.213)$ & $(0.117)$ \\
\hline \multirow[t]{2}{*}{ Smoking frequently } & 0.932 & $1.272^{* *}$ & 1.040 & $1.484^{* *}$ & 0.920 & 1.217 \\
\hline & $(0.125)$ & $(0.131)$ & $(0.247)$ & $(0.274)$ & $(0.147)$ & $(0.149)$ \\
\hline \multirow[t]{2}{*}{ Getting drunk frequently } & 0.766 & 0.847 & 1.411 & 0.720 & 0.374 & 0.908 \\
\hline & $(0.169)$ & $(0.113)$ & $(0.400)$ & $(0.162)$ & $(0.109)$ & $(0.154)$ \\
\hline \multirow[t]{2}{*}{ Constant } & $3.134^{* * *}$ & 1.572 & $3.429^{* *}$ & $4.067^{* * *}$ & - & - \\
\hline & $(1.336)$ & $(0.598)$ & $(1.806)$ & $(2.042)$ & - & - \\
\hline \multicolumn{7}{|l|}{ Younger partner } \\
\hline \multirow[t]{2}{*}{ Women } & $0.133^{* * *}$ & $0.115^{* * *}$ & - & - & - & - \\
\hline & $(0.0244)$ & $(0.0159)$ & - & - & - & - \\
\hline \multirow[t]{2}{*}{ Friend } & 0.915 & 0.546 & 0.879 & 0.488 & - & - \\
\hline & $(0.582)$ & $(0.232)$ & $(0.571)$ & $(0.227)$ & - & - \\
\hline \multirow[t]{2}{*}{ Boy/girl friend } & 1.651 & 0.832 & 1.513 & 0.694 & - & - \\
\hline & $(1.011)$ & $(0.338)$ & $(0.945)$ & $(0.310)$ & - & - \\
\hline \multirow[t]{2}{*}{ Mean sexual debut } & $1.445^{* *}$ & $1.658^{* * *}$ & $1.406^{*}$ & $1.574^{* * *}$ & - & - \\
\hline & $(0.271)$ & $(0.202)$ & $(0.283)$ & $(0.203)$ & - & - \\
\hline \multirow[t]{2}{*}{ Late sexual debut } & $2.354^{* * *}$ & $2.307^{* * *}$ & $2.571^{* * *}$ & $2.179^{* * *}$ & - & - \\
\hline & $(0.462)$ & $(0.297)$ & $(0.558)$ & $(0.301)$ & - & - \\
\hline \multirow[t]{2}{*}{ No (single earner) } & 1.106 & 1.163 & 0.902 & 1.166 & - & - \\
\hline & $(0.155)$ & $(0.114)$ & $(0.142)$ & $(0.124)$ & - & - \\
\hline
\end{tabular}


Table 7 Results of multinomial (for both genders and men) and binary (for women) logistic regression models (relative risks and odd ratios) of partners' age differences at first sex on key determinants and control variables for 2000 and 2017 SELFY waves (Continued)

\begin{tabular}{|c|c|c|c|c|c|c|}
\hline & \multicolumn{2}{|c|}{ Both genders } & \multicolumn{2}{|l|}{ Males } & \multicolumn{2}{|l|}{ Females } \\
\hline & $\begin{array}{l}\text { Model } 1 \\
2000\end{array}$ & $\begin{array}{l}\text { Model } 2 \\
2017\end{array}$ & $\begin{array}{l}\text { Model } 3 \\
2000\end{array}$ & $\begin{array}{l}\text { Model } 4 \\
2017\end{array}$ & $\begin{array}{l}\text { Model } 5 \\
2000\end{array}$ & $\begin{array}{l}\text { Model } 6 \\
2017\end{array}$ \\
\hline \multirow{2}{*}{$\begin{array}{l}\text { Balanced relationship } \\
\text { (father) }\end{array}$} & 1.050 & 1.051 & 1.072 & 1.017 & - & - \\
\hline & $(0.174)$ & $(0.130)$ & $(0.210)$ & $(0.137)$ & - & - \\
\hline \multirow{2}{*}{$\begin{array}{l}\text { Balanced relationship } \\
\text { (mother) }\end{array}$} & 0.868 & 0.992 & 0.782 & 0.781 & - & - \\
\hline & $(0.171)$ & $(0.209)$ & $(0.183)$ & $(0.187)$ & - & - \\
\hline \multirow[t]{2}{*}{ Working regularly } & 1.224 & 1.061 & 1.254 & 1.044 & - & - \\
\hline & $(0.246)$ & $(0.131)$ & $(0.292)$ & $(0.138)$ & - & - \\
\hline \multirow[t]{2}{*}{ Older brother } & 0.889 & 0.937 & 0.820 & 1.019 & - & - \\
\hline & $(0.143)$ & $(0.0959)$ & $(0.148)$ & $(0.113)$ & - & - \\
\hline \multirow[t]{2}{*}{ Smoking frequently } & 0.841 & 1.009 & 0.826 & 1.008 & - & - \\
\hline & $(0.152)$ & $(0.129)$ & $(0.165)$ & $(0.137)$ & - & - \\
\hline \multirow[t]{2}{*}{ Getting drunk frequently } & 0.971 & 0.790 & 0.983 & $0.715^{* *}$ & - & - \\
\hline & $(0.230)$ & $(0.118)$ & $(0.254)$ & $(0.112)$ & - & - \\
\hline \multirow[t]{2}{*}{ Constant } & $0.319^{*}$ & 0.471 & 0.404 & 0.747 & $37.77^{* * *}$ & $2.684^{*}$ \\
\hline & $(0.206)$ & $(0.217)$ & $(0.269)$ & $(0.382)$ & (39.65) & $(1.571)$ \\
\hline Observations & 2530 & 4,397 & 901 & 1,992 & 1629 & 2,405 \\
\hline Pseudo R-squared & 0.225 & 0.207 & 0.0719 & 0.0422 & 0.0472 & 0.0231 \\
\hline Log Lik & -1902 & -3593 & -843.9 & -1793 & -900.2 & -1555 \\
\hline
\end{tabular}

Notes: Robust Standard Errors (RSE) in parentheses

${ }^{* * *} p<0.01$

${ }^{* *} p<0.05$

${ }^{*} p<0.1$

male issue. However, if so, it is more likely that happened with a stranger than with the own girlfriend or with a friend (models 3 and 4-older partner). Moreover, the relative risk of being involved with an older partner rather than a sameage partner at first sex is lower for males with a mean debut respect to those who initiated their sexual lives earlier. The type of relationship seems to be important for males having had first sex with older partners but not for those involved with younger partners (models 3 and 4).

This variable did not appear significant on model specifications on females' likelihood of have had first sex with an older partner. Although, a significantly lower risk of having had the first sexual intercourse with an older partner is observed among females with a mean sexual debut (more than forty percent lower), which is even lower among those having a late sexual debut relative to those having an early debut (models 5 and 6).

It is interesting to note that the likelihood of having had first sex with an older partner is also higher (25\% higher) for females with at least one older brother if compared to females without older brothers. Lastly, our findings highlight a higher likelihood of first sex relationships among same-age partners relative to intercourse with older partners through SELFY waves, but little changes on the variables influencing such relationships were observed. 


\section{Concluding remarks}

Our paper shed some lights on age differences between partners at first sex corroborating and extending findings from the previously recalled research (see section "Theoretical background") regarding relationship dynamics of young adults.

Firstly, our results are in line with previous research regarding gendered age preferences, showing that female students are more likely to be involved with older partners at first sex than do males, while male students are more likely to have had their first sexual encounter with a younger partner than females (Wiederman, 1993; Kenrick et al., 1995; Buunk et al., 2001, 2002; Ní Bhrolcháin \& Sigle-Rushton, 2005; Mercer et al., 2006; Antfolk et al., 2015; Antfolk, 2017).

We also found that having older brothers significantly increase females' likelihood of having had first sex with an older male partner. In other words, girls having an older brother in the family might be also in contact with a market plenty of brothers' friends, having more opportunities to socially interact with them than their counterparts with a more restricted social universe (female students without older male siblings). This finding, in line with the findings of Bozon and Rault (2012), seems to be pointing out that age differences might be also responsive to meeting places and that the extension of the family network might be an important determinant of female age-discordant first sex relationships.

Confirming the results obtained by Dalla-Zuanna et al. (2019), our analyses show that the gap between boys and girls in the age at first sexual intercourse in Italy is "closing." The observed increase on age homogeneity in first sexual relationships between the SELFY wave of 2000 and the one of 2017 might be explained by changes occurred in the mate selection context, given that younger generations live embedded on a social media context characterized by a greater exposure to same-age partners.

In fact, not only social exposure to a market of potential partners (surrounding social context) but also to a context ruled by communication technologies and social media might bring potential partners together. Such context might facilitate partners' search and give a structure to pre-dating social relations. Exposure to new ways of communication among peers seems to be creating a different social innovation mate search strategy (Schroeder, 2018). The youngest generations have witnessed more profound and irreversible technological changes than any previous generation. Online social life through the internet became commonplace even in the early adolescent years, deeply transforming the environment of mating (Blais, Craig, Pepler, \& Connolly, 2008). Thus, we highlight that the role of the "traditional" context, where mate availability is shaped by direct interpersonal contacts, is nowadays (and particularly during the period between the two waves of the SELFY surveys) matched with the more "innovative" digital context, in which contacts are less direct and embedded in "digital" social forms. Clearly, there are several factors shaping first sexual intercourse dynamics, but we believe that both the matching and the interacting processes with a potential first sexpartner are also strongly shaped by social contexts that act as main channels for establishing relationships.

Lastly, our results indicate that a "feminization" of male behavior within the couple is occurring together with a "masculinization" of girls' sexual behaviors. Previous research has shown that similar processes are taking place also in male and female attitudes and opinions and that they also concern aspects outside a couple relationship (see, among 
others, Dalla-Zuanna et al., 2019). As some authors have stressed, the sexuality of youths is influenced by the level of gender equality both in the family and in the social context in which they live (Marston \& King, 2006; De Meyer et al., 2014). This let us to hypothesize that the observed convergence might also be considered as an expression of deeper transformations within the relationships between men and women, taking place in Italy in the last decades, which are triggering more egalitarian norms and behaviors in different socio-economic spheres such as work, family and interpersonal relationships.

Unfortunately, due to the characteristics of available data, we were not able to approach the meanings given to the established relationship, the attributes that were sought on a partner, the match between attributes sought, and those actually found, or if the sexual relationship evolved to a romantic relationship. Consequently, we cannot state if observed differences are a matter of mate availability or a matter of individual preferences. Additionally, we were not able to test mate selection theories, given the high level of specificity of our subject of study (age differences between partners at first sex).

We are also completely aware of sample limitations of SELFY waves in terms of representativeness. Thanks to the work of Dalla-Zuanna et al. (2019) we know that SELFY respondents experienced their first sexual intercourse later than their less educated peers, were sexually less precocious, particularly men, and held more traditional sexual behaviors than their peers enrolled in political sciences university courses. Unfortunately, due to the lack of comparable data, we were not able to test whether differences observed in first sex age-discordant relationships are due to a sort of sample selection or can be generalized to the young population as a whole. Although when comparing our results with those obtained by similar surveys conducted in other European countries (France, UK, Scotland, Northern Ireland), we have not found evidence supporting the existence of a sample selection (being SELFY respondents college students). Instead, our results seem to converge into a broader European framework, according to the following aspects. Firstly, most young individuals sexually debut with the own boy-girl friend (Manning et al., 2000; Henderson et al., 2002; Wight et al., 2008); secondly, men are more likely than women to have first sex with a stranger or with someone they barely know (Schubotz et al., 2004; Wight et al., 2008); thirdly, women's first sexual experience mostly occurred with an older partner and, lastly, first sex within a downward age-discordant relationship (with a younger partner) is more common among men (Mercer et al., 2006; Wight et al., 2008; Bozon \& Rault, 2012). However, a note of caution is due here since SELFY samples only included college students enrolled in courses of economics and statistics. We are aware of the importance of the context in which the first sexual experience is embedded, especially regarding the role of potential meeting places and communication technologies on mate matching and partner search during youth. Regrettably, SELFY questionnaires have not included questions neither on how and where partners met each other nor on the use of technology and, therefore, we were not able to analyze these issues. Further studies, taking these variables into account, will need to be undertaken.

Our results invite research on the subject to carefully consider not only the pathways that bring young adults together but also the context in which sexual initiation is occurring because these might be having a profound influence on the type of relationship formed. 


\section{Acknowledgements}

Not applicable.

\section{Authors' contributions}

The authors have contributed equally to the work. The author(s) read and approved the final manuscript.

\section{Funding}

No specific funding has been provided for the research.

\section{Availability of data and materials}

The datasets analyzed during the current study are available from the corresponding author on reasonable request.

\section{Competing interests}

Authors have not competing interests.

Received: 10 December 2019 Accepted: 8 July 2020

Published online: 24 August 2020

\section{References}

Antfolk, J. (2017). Age limits: Men's and women's youngest and oldest considered and actual sex partners. Evolutionary Psychology, 15(1).

Antfolk, J., Salo, B., Alanko, K., Bergen, E., Corander, J., Sandnabba, N. K., \& Santtila, P. (2015). Women's and men's sexual preferences and activities with respect to the partner's age: Evidence for female choice. Evolution and Human Behavior, 36(1), 73-79.

Aspy, C. B., Vesely, S. K., Oman, R. F., Rodine, S., Marshall, L., \& McLeroy, K. (2007). Parental communication and youth sexual behaviour. Journal of adolescence, 30(3), 449-466.

Bajos, N., Bozon, M., Beltzer, N., Laborde, C., Andro, A., Ferrand, M., ... Levinson, S. (2010). Changes in sexual behaviours: From secular trends to public health policies. Aids, 24(8), 1185-1191.

Bech-Sørensen, J., \& Pollet, T. V. (2016). Sex differences in mate preferences: A replication study, 20 years later. Evolutionary Psychological Science, 2(3), 171-176.

Bellis, M. A., Hughes, K., Calafat, A., Juan, M., Ramon, A., Rodríguez, J. A., ... Phillips-Howards, P. (2008). Sexual uses of alcohol and drugs and the associated health risks: A cross sectional study of young people in nine European cities. BMC Public Health, 8, 155

Billari, F. C., Caltabiano, M., \& Dalla-Zuanna, G. (Eds.) (2007). Sexual and affective behaviour of students. An international research. Padova: Cleup.

Blackwell, D. L., \& Lichter, D. T. (2004). Homogamy among dating, cohabiting, and married couples. The Sociological Quarterly, 45(4), 719-737.

Blais, J. J., Craig, W. M., Pepler, D., \& Connolly, J. (2008). Adolescents online: The importance of Internet activity choices to salient relationships. Journal of youth and adolescence, 37(5), 522-536.

Blau, P. M. (1964). Exchange and power in social life. New York: Wiley.

Blau, P. M., \& Schwartz, J. E. (1984). Crosscutting social circles. London: Academic.

Borawski, E. A., levers-Landis, C. E., Lovegreen, L. D., \& Trapl, E. S. (2003). Parental monitoring, negotiated unsupervised time, and parental trust: The role of perceived parenting practices in adolescent health risk behaviors. Journal of Adolescent Health, 33(2), 60-70.

Bozon, M. (2018). Sociologie de la sexualité. Paris: Armand Colin.

Bozon, M., \& Kontula, O. (1998). Sexual initiation and gender: A cross-cultural analysis of trends in the 20th century. Sexual behaviour and HIV/AIDS. In M. Hubert, N. Bajos, \& T. Sandfort (Eds.), Europe: Comparisons of National Surveys, (pp. 37-67). London: UCL Press.

Bozon, M., \& Rault, W. (2012). From sexual debut to first union. Where do young people in France meet their first partners? Population, 67(3), 377-410.

Brauner-Otto, S. R., \& Axinn, W. G. (2010). Parental family experiences, the timing of first sex, and contraception. Social science research, 39(6), 875-893.

Bruckner, H., \& Bearman, P. (2003). Dating behavior and sexual activity of young adolescents: Analyses of the National Longitudinal Study of Adolescent Health. In B. Albert, S. Brown, \& C. M. Flanigan (Eds.), 14 and Younger: The Sexual Behaviors of Young Adolescents, (pp. 31-56). Washington, DC: National Campaign to Prevent Teen Pregnancy.

Buss, D. M. (1989). Sex differences in human mate preferences: Evolutionary hypotheses tested in 37 cultures. Behavioral and Brain Sciences, 12, 1-49.

Buss, D. M., \& Schmitt, D. P. (1993). Sexual strategies theory: an evolutionary perspective on human mating. Psychological Review, 100, 204-232.

Buunk, B. P., Dijkstra, P., Fetchenhauer, D., \& Kenrick, D. T. (2002). Age and gender differences in mate selection criteria for various involvement levels. Personal Relationships, 9(3), 271-278.

Buunk, B. P., Dijkstra, P., Kenrick, D. T., \& Warntjes, A. (2001). Age preferences for mates as related to gender, own age, and involvement level. Evolution and Human Behaviour, 22, 241-250. https://doi.org/10.1016/S1090-5138(01)00065-4.

Caltabiano, M., Dalla-Zuanna, G., \& Rosina, A. (2006). Interdependence between sexual debut and church attendance in Italy. Demographic Research, 14(19), 453-484.

Conroy-Beam, D., \& Buss, D. M. (2019). Why is age so important in human mating? Evolved age preferences and their influences on multiple mating behaviors. Evolutionary Behavioral Sciences, 13(2), 127.

Cooper, M. L. (2002). Alcohol use and risky sexual behavior among college students and youth: evaluating the evidence. Journal of Studies on Alcohol, 14, 101-117.

Dalla-Zuanna, G., Caltabiano, M., Minello, A., \& Vignoli, D. (2019). Catching up! The sexual opinions and behaviour of Italian students (2000-2017). DISIA Working Paper 2019/02: Università degli Studi di Firenze. 
Dalla-Zuanna, G., \& Crisafulli, C. (Eds.) (2004). Sexual behaviour of Italian students. Messina: University of Messina.

Darroch, J. E., Landry, D. J., \& Oslak, S. (1999). Age differences between sexual partners in the United States. Family Planning Perspectives., 131(4), 160-167.

De Meyer, S., Jaruseviciene, L., Zaborskis, A., Decat, P., Vega, B., Cordova, K., ... Michielsen, K. (2014). A cross-sectional study on attitudes toward gender equality, sexual behavior, positive sexual experiences, and communication about sex among sexually active and non-sexually active adolescents in Bolivia and Ecuador. Global health action, 7(1), 24089.

Dogan, S. J., Stockdale, G. D., Widaman, K. F., \& Conger, R. D. (2010). Developmental relations and patterns of change between alcohol use and number of sexual partners from adolescence though adulthood. Developmental Psychology, 44, 1747-1759.

Doku, D. (2012). Substance use and risky sexual behaviours among sexually experienced Ghanaian youth. BMC public health, 12(1), 571.

Eagly, A. H., \& Wood, W. (1999). The origins of sex differences in human behavior: Evolved dispositions versus social roles. American Psychologist, 54(6), 408-423. https://doi.org/10.1037/0003-066X.54.6.408.

Eagly, A. H., Wood, W., \& Diekman, A. B. (2000). Social role theory of sex differences and similarities: A current appraisal. In T. Eckes, \& H. M. Trautner (Eds.), The developmental social psychology of gender, (pp. 123-174). Mahwah, NJ: Lawrence Erlbaum Publishers.

Eckhard, J., \& Stauder, J. (2019). Partner market opportunities and union formation over the life course. A comparison of different measures. Population, Space and Place, 25(4), e2178. https://doi.org/10.1002/psp.2178.

Edwards, J. N. (1969). Familial behavior as social exchange. Journal of Marriage and the Family, 31(3), 518-526.

Fahlén, S. (2015). Gender equality within dual-earner and dual-career couples across different policy regimes and norm systems in Europe. Families and Societies, 48(48), 1-21.

Ford, K., Sohn, W., \& Lepkowski, J. (2001). Characteristics of adolescents' sexual partners and their association with use of condoms and other contraceptive methods. Family Planning Perspectives, 33(3), 100-105 \& 132.

Ford, K., Sohn, W., \& Lepkowski, J. (2003). Ethnicity or race, area characteristics, and sexual partner choice among American adolescents. Journal of Sex Research, 40(2), 211-218.

Gabrielli, G., Pace, R., \& Paterno, A. (2004). First sexual intercourse among interviewees and partners: age, opinions and behaviour in matematching. In G. Dalla-Zuanna and C. Crisafulli (Ed.), Sexual Behaviour of Italian Students (pp. 341-360). Dipartimento di Scienze Statistiche, Università di Messina.

Glie, D. A. (1999). Measuring contraceptive use patterns among teenage and adult women. Family Planning Perspectives, 31(2), $73-80$.

Greenberg, J., Magder, L., \& Aral, S. (1992). Age at first coitus: A marker for risky sexual behavior in women. Sexually Transmitted Diseases, 19, 331-334.

Hawes, Z. C., Wellings, K., \& Stephenson, J. (2010). First heterosexual intercourse in the United Kingdom: A review of the literature. Journal of sex research, 47(2-3), 137-152.

Henderson, M., Wight, D., Raab, G., Abraham, C., Buston, K., Hart, G., \& Scott, S. (2002). Heterosexual risk behaviour among young teenagers in Scotland. Journal of adolescence, 25(5), 483-494.

Heywood, W., Patrick, K., Smith, A. M., \& Pitts, M. K. (2015). Associations between early first sexual intercourse and later sexual and reproductive outcomes: A systematic review of population-based data. Archives of sexual behavior, 44(3), 531-569. Huebner, A. J., \& Howell, L. W. (2003). Examining the relationship between adolescent sexual risk-taking and perceptions of monitoring, communication, and parenting styles. Journal of adolescent health, 33(2), 71-78.

Huebner, A. J., \& Howell, L. W. (2003). Examining the relationship between adolescent sexual risk-taking and perceptions of monitoring, communication, and parenting styles. Journal of adolescent health, 33(2), 71-78.

Kaestle, C. E., Morisky, D. E., \& Wiley, D. J. (2002). Sexual intercourse and the age difference between adolescent females and their romantic partners. Perspectives on sexual and reproductive health, 304-309.

Kalmijn, M. (1998). Intermarriage and homogamy: Causes, patterns, trends. Annual review of sociology, 24(1), 395-421.

Kenrick, D. T., Gabrielidis, C., Keefe, R. C., \& Cornelius, J. (1996). Adolescents' age preferences for dating partners: Support for an evolutionary model of life-history strategies. Child Development, 67, 1499-1511.

Kenrick, D. T., Keefe, R. C., Bryan, A., Barr, A., \& Brown, S. (1995). Age preferences and mate choice among homosexuals and heterosexuals: A case for modular psychological mechanisms. Journal of Personality and Social Psychology, 69, $1166-1172$.

Kenrick, D. X., \& Keefe, R. C. (1992). Age preferences in mates reflect sex differences in human reproductive strategies. Behavioral and Brain Sciences, 15, 75-133.

Koon-Magnin, S., Kreager, D. A., \& Ruback, R. B. (2010). Partner age differences, educational contexts and adolescent female sexual activity. Perspectives on sexual and Reproductive Health, 42(3), 206-213.

Lee, J. K., Jennings, J. M., \& Ellen, J. M. (2003). Discordant sexual partnering: A study of high-risk adolescents in San Francisco. Sexually Transmitted Diseases, 30, 234-240.

Liu, G., Hariri, S., Bradley, H., Gottlieb, S. L., Leichliter, J. S., \& Markowitz, L. E. (2015). Trends and patterns of sexual behaviors among adolescents and adults aged 14 to 59 years, United States. Sexually transmitted diseases, 42(1), $20-26$.

Loftus, J., Kelly, B. C., \& Mustillo, S. A. (2013). Predictors of entry into age-discordant relationships among adolescent girls. Deviant Behavior, 34(7), 513-533.

Lomba, L., Apóstolo, J., \& Mendes, F. (2009). Drugs and alcohol consumption and sexual behaviours in night recreational settings in Portugal. Adicciones, 21(4), 309-326.

Longmore, M. A., Eng, A. L., Giordano, P. C., \& Manning, W. D. (2009). Parenting and adolescents' sexual initiation. Journal of Marriage and Family, 71(4), 969-982.

Manlove, J., Terry-Humen, E., \& Ikramullah, E. (2006). Young teenagers and older sexual partners: Correlates and consequences for males and females. Perspectives on Sexual and Reproductive Health, 38(4), 197-207.

Manning, W. D., Longmore, M. A., \& Giordano, P. C. (2000). The relationship context of contraceptive use at first intercourse. Family planning perspectives, 104-110.

Marston, C., \& King, E. (2006). Factors that shape young people's sexual behaviour: A systematic review. Lancet, 368, 1581-1586.

Mercer, C. H., Wellings, K., Macdowall, W., Copas, A. J., McManus, S., Erens, B., ... Johnson, A. M. (2006). First sexual partnerships - age differences and their significance: empirical evidence from the 2000 British National Survey of Sexual Attitudes and Lifestyles ('Natsal 2000'). Journal of Adolescent Health, 39(1), 87-95. 
Miller, K., Clark, L., \& Moore, J. (1997). Sexual initiation with older male partners and subsequent HIV risk behavior among female adolescents. Family Planning Perspectives, 29(5), 212-214. https://doi.org/10.2307/2953397.

Ní Bhrolcháin, M. (2006). The age difference between partners: A matter of female choice? In C. Sauvain-Dugerdil, H. Leridon, \& N. Mascie-Taylor (Eds.), Human clocks: The bio-cultural meanings of age, (pp. 289-312). Bern: Peter Lang.

Ní Bhrolcháin, M., \& Sigle-Rushton, W. (2005). Partner supply in Britain and the US: Estimates and gender contrasts. Population (English Edition), 60(1-2), 37-64.

Oudekerk, B. A., Guarnera, L. A., \& Reppucci, N. D. (2014). Older opposite-sex romantic partners, sexual risk, and victimization in adolescence. Child Abuse \& Neglect, 38(7), 1238-1248.

Parkes, A., Henderson, M., Wight, D., \& Nixon, C. (2011). Is parenting associated with teenagers' early sexual risk-taking, autonomy and relationship with sexual partners? Perspectives on sexual and reproductive health, 43(1), 30-40.

Potki, R., Ziaei, T., Faramarzi, M., Moosazadeh, M., \& Shahhosseini, Z. (2017). Bio-psycho-social factors affecting sexual selfconcept: A systematic review. Electron Physician, 9(9), 5172-5178.

Poulin, C., \& Graham, L. (2001). The association between substance use, unplanned sexual intercourse and other sexual behaviours among adolescent students. Addiction, 96(4), 607-621.

Ramrakha, S., Paul, C., Bell, M. L., Dickson, N., Moffitt, T. E., \& Caspi, A. (2013). The relationship between multiple sex partners and anxiety, depression, and substance dependence disorders: A cohort study. Archives of sexual behavior, 42(5), 863-872.

Ritchwood, T. D., Ford, H., DeCoster, J., Sutton, M., \& Lochman, J. E. (2015). Risky sexual behavior and substance use among adolescents: A meta-analysis. Children and youth services review, 52, 74-88.

Rodgers, K. B. (1999). Parenting processes related to sexual risk-taking behaviors of adolescent males and females. Journal of Marriage and the Family, 61(1), 99-109.

Ryan, S., Franzetta, K., Manlove, J. S., \& Schelar, E. (2008). Older sexual partners during adolescence: links to reproductive health outcomes in young adulthood. Perspectives on sexual and reproductive health, 40(1), 17-26.

Santelli, J. S., Robin, L., Brener, N. D., \& Lowry, R. (2001). Timing of alcohol and other drug use and sexual risk behaviors among unmarried adolescents and young adults. Family planning perspectives, 200-205.

Schroeder, R. (2018). Social theory after the internet. London: University College London Press.

Schubotz, D., Rolston, B., \& Simpson, A. (2004). Sexual behaviour of young people in Northern Ireland: first sexual experience. Critical Public Health, 14(2), 177-190.

Schwartz, C. (2013). Trends and variation in assortative mating: Causes and consequences. Annual Review of Sociology, 39, $451-470$.

Schwartz, C. R., \& Graf, N. L. (2009). Assortative matching among same-sex and different-sex couples in the United States, 1990-2000. Demographic Research, 21, 843-878. doi.org/https://doi.org/10.4054/DemRes.2009.21.28

Scott-Sheldon, L. A., Carey, K. B., Cunningham, K., Johnson, B. T., Carey, M. P., \& Research Team, M. A. S. H. (2016). Alcohol use predicts sexual decision-making: a systematic review and meta-analysis of the experimental literature. AIDS and Behavior, 20(1), 19-39.

Senn, T. E., \& Carey, M. P. (2011). Age of partner at first adolescent intercourse and adult sexual risk behavior among women. Journal of Wome's Health, 20(1), 61-66.

Staras, S. A., Cook, R. L., \& Clark, D. B. (2009). Sexual partner characteristics and sexually transmitted diseases among adolescents and young adults. Sexually Transmitted Diseases, 36(4), 232-238.

Stauder, J. (2008). Opportunitäten und Restriktionen des Kennenlernens. Zur sozialen Vorstrukturierung der Kontaktgelegenheiten am Beispiel des Partnermarkts. Kölner Zeitschrift für Soziologie und Sozialpsychologie, 60(2), 265-286.

Stauder, J. (2014). The social structure of opportunities for contact and interaction and strategies for analysing friendship. In K. Thomas et al. (Eds.), Der Partnermarkt und die Gelegenheiten des Kennenlernens. Der Partnermarktsurvey, (pp. 221-241). Wiesbaden: Springer.

Van de Putte, B., Van Poppel, F., Vanassche, S., Sanchez, M., Jidkova, S., Eeckhaut, M., ... Matthijs, K. (2009). The rise of age homogamy in 19th century Western Europe. Journal of Marriage and Family, 71(5), 1234-1253.

VanOss Marín, B. V., Coyle, K. K., Gómez, C. A., Carvajal, S. C., \& Kirby, D. B. (2000). Older boyfriends and girlfriends increase risk of sexual initiation in young adolescents. Journal of Adolescent Health, 27(6), 409-418.

Volpe, E. M., Hardie, T. L., Cerulli, C., Sommers, M. S., \& Morrison-Beedy, D. (2013). What's age got to do with it? Partner age difference, power, intimate partner violence, and sexual risk in urban adolescents. Journal of interpersonal violence, 28(10), 2068-2087.

Wiederman, M. W. (1993). Evolved gender differences in mate preferences: Evidence from personal advertisements. Ethology and Sociobiology, 14(5), 331-351.

Wight, D., Parkes, A., Strange, V., Allen, E., Bonell, C., \& Henderson, M. (2008). The quality of young people's heterosexual relationships: A longitudinal analysis of characteristics shaping subjective experience. Perspectives on Sexual and Reproductive Health, 40, 226-237.

Wight, D., Williamson, L., \& Henderson, M. (2006). Parental influences on young people's sexual behaviour: A longitudinal analysis. Journal of adolescence, 29(4), 473-494.

Young, J. A., Critelli, J. W., \& Keith, K. W. (2005). Male age preferences for short-term and long-term mating. Sexualities Evolution \& Gender, 7, 83-93.

Zavodny, M. (2001). The effect of partners' characteristics on teenage pregnancy and its resolution. Family Planning Perspectives, 192-205.

\section{Publisher's Note}

Springer Nature remains neutral with regard to jurisdictional claims in published maps and institutional affiliations. 